\title{
Evolution of Rhinology
}

\author{
S. K. Kaluskar
}

"The longer you look back, the further you can look" -W. Churchill

Summary The study of the nose is as old as civilisation. Various conditions affecting its structure and function has been documented in Edwin Smith Papyrus in hieroglyphic script, an Egyptian writing system of the mid -4 th Millennium BC.The major contribution for the complete reconstruction of the nose originated in India by Sushruta in around $600 \mathrm{BC}$. Writing in Sanskrit in the form of verses he described in detail the technique of total reconstruction, which is still being practiced today as Indian Rhinoplasty.This surgical reconstruction paved the way to modern plastic surgery in Europe and United States in 18th century. Sushruta contributed not only to the plastic surgery of the nose, but described entire philosophy of Head and Neck and other surgery as well. Other notable contributors were Greek physicians, Hippocrate and Galen, and at the birth of the Christianity, Celsus wrote eight books of medical encyclopaedia, which described various conditions affecting nose.

Septal and Sinus surgery, in comparison to rhinoplasty did not develop until 17 th century. Septal surgery began with total septectomy, sub mucous resection by Killian \& Freer in early 20th century and later septoplasty by Cottle in middle of 20th century.

Sinus surgery probably originated in Egypt, where instruments were used to remove brain through the ethmoid sinuses as part of the mummification process. In 18th century, empyema of the maxillary sinus was drained through

Based on L.H. Hiranandani Oration-

delivered by Dr. S.K. Kaluskar, AOI 2001 at Banglore, India

S. K. Kaluskar

Consultant ORL, Tyrone County Hospital,

Omagh,

N. Ireland, UK the tooth socket or anterior wall of the sinus, which lead to the evolution of radical procedures of removal of mucous membrane and inferior meatal antrostomy. In the late 20th century, improved understanding of the mucociliary mechanism described by Prof. Messerklinger and Nasal Endoscopy described by Prof. Draf with the development of fibre optics and CT imaging, heralded a new era, which evolved in functional endoscopic sinus surgery. New technology further enhanced the scope of endoscope being used "around and beyond" the nose.

\section{Evolution of rhinology}

Reconstruction of the nose is as old as recorded civilisation. Today few people appreciate the immense contribution of India made in the field of rhinology. Reconstruction of the nose with forehead and cheek flap originated and progressed in India, which subsequently created great deal of interest in Europe and North America. Later on reconstructive surgery, which began in India, paved the way to the evolution of corrective rhinoplasty.

\section{The ancient time}

A prominent structure, the nose, in the middle of the face has acquired a unique status socially, sexually, aesthetically and not to mention a very important physiologically. The presence of para nasal sinuses is documented in ancient Egypt where instruments were used to remove brain through the ethmoid sinuses in the process of mummification.

In prehistoric times babies born with nose defects were considered as evil omen and were killed at birth. Loss of nose reduced acceptability in the society. Social crimes such as adultery and sex offenders were punished by amputation of the nose. Large noses were considered as a sexual symbol as ancient Roman Quinn Joanna only preferred men with large noses! In Indian culture traditionally women 
beautified nose with various sizes of ornaments. In 15th century Leonardo De Vinci, a greatest figure of the Italian Renaissance, a painter, sculptor, architect, engineer and scientist set up principals of beauty. Physiologically the nose is at the entrance of the respiratory tract and is vital for the function of respiration, humidification, and filtration.

Reconstruction of the fractured nasal bones has been documented in Edwin Smith Papyrus, which is an Egyptian script written at around $3000 \mathrm{BC}$. The treatment of the fractured nasal bones was described as removal of blood clots and forcing displaced nasal bones back to its original position. The nose was packed with linen saturated with grease and honey. The nasal bones were kept in position with hollow wooden tube.

The ancient Indian Medicine is based on Vedic literature (1600 BC to $800 \mathrm{BC}$.), the ancient Holy Scriptures of Hindu philosophy. There are four main Vedic scripture, ie, Rig Veda, Yajur Veda, Sam Veda and Atharva Veda. The Ayurveda (Knowledge of life) derived from Athrva Veda has two main treatises. Charak Samhita, which deals with the medicine and Sushrut Samhita, written by Prof. Sushruta is pertaining to Surgery. Hessler later translated Sushruta Samhita in Latin in 1844.

Prof. Sushruta was a highly moral and innovative surgeon and wrote Sushruta Samhita in Sanskrit ( ? 800 BC) in the form of verses in India along the banks of the holy river Ganges. He passionately believed that the anatomy was the foundation of successful surgery and made his students perform dissection. He described 24 arteries, veins, nerves and various ducts in the body. He designed tubular nasal speculum called "Netiyantra" and diagnosed 31 diseases of the nose including atrophic rhinitis. He recommended acid vapours and oil for the treatment of atrophic rhinitis. Mutilating noses were seen as a result of social crime these were reconstructed with forehead and cheek flap, the very first step in the evolution of modern plastic surgery. Sushruta used leaf patterns of the nose to measure the various dimensions prior to nasal reconstruction. Tissues were sutured with hoarse hairs.

Sushruta provided minute details of surgical indications, contraindications, techniques, pre and postoperative care, complications and the type of diet to be taken following surgery. He classified surgical procedures as excision, incision, scarification, puncture, probing, extraction, drainage/ evacuation and described suturing. He practiced surgical procedures on watermelons, cucumbers, bladder, dead animal, and on leather pouch. He performed venesection on a Lotus stem, and practiced extraction of teeth by taking out jackfruit seeds.

He emphasized preoperative preparation and cleanliness. He fumigated operating room by fumes of mustard, butter and salt. The anaesthesia was provided by alcohol intoxication. He insisted that the surgical instruments were made of "pure iron" and designed some 125 instruments, which were classified as sharp and blunt. On the basis of beaks of the various birds he classified these instruments as forceps, pincers, tubes, hooks, catheters and sounds. He described 14 types of dressings including splints fashioned from branches of bamboo trees, and various tree barks. Sutures were prepared from fibres from Indian hemp, a type of plant belonging to mulberry family, yielding a coarse fibre, a narcotic drug and oil making a sedative suture ! Some sutures were prepared from hair of hoarse, strips of leather and cotton.

Although Sushruta was mainly innovative in Head and Neck Surgery( Uttertanman), he also described laperotomy, intestinal obstruction and repair, herniorrhaphy, harelip, caesarean section and couching of opaque cataract along with 15 methods of otoplasty procedures some of which are practiced today. Truly surgery reached masterful levels in ancient India.

Sushruta put forward humoral theory of body fluid ie, air, bile and phlegm and stressed the importance of man's relationship to the cosmos through the balance of the body fluids. Later Greeks practised medicine for a long time on these principals.

One physician, Hippocrates at about $460 \mathrm{BC}$, who was aptly named as "Father of Medicine" dominated Greek period. He set out high ethical conduct for the physician, emphasized the importance of observation and diagnosis, prognosis, recordings, and like Sushruta believed in dietary and environmental treatment for the illness. Hippocrates maintained that most diseases have tendency to natural cure. Regarding nasal fractures he advocated that nasal fracture should be reduced in 24 to $36 \mathrm{hrs}$ and both internal and external splints should be applied in the postoperative period. In cases of polyps he described, "sponge method " of nasal polypectomy.

At the birth of the Christianity Aulus Celsus, a prominent Roman physicians and Galen, a brilliant Greek physician, described tissue transplantation, excision of scar tissue and use of plaster for fixation in nasal surgery. Celsus in $\mathrm{AD}$ 30 wrote several books of medical encyclopaedia in Latin. In the book VI and VII he described diseases of the ear, and surgical anatomy of the nose and olfactory pathways through the cribriform plate of the ethmoid bone. Later on Galen (AD 131) recognised nasal physiology and the importance of warming, humidification of inspired air in relation to nasal physiology.

\section{The renaissance period}

Following the fall of Roman Empire in 5th Century ie, during the dark ages very few changes took place but with the renaissance, the transition from middle ages to the modern world, rhinoplasty once again was brought into light along with the revival of the arts and literature. One of the greatest figure of Italian renaissance was Leonardo De Vinci (1452-1519 AD) who described the nasal aesthetics 
in relation to the face. He studied maxillary and frontal sinuses after injecting wax and established aesthetic proportions of the face. He was a true genius as a painter, sculptor, architect, engineer and a scientist. His notebooks and drawings show an immensely inventive and enquiring mind, studying aspect of the natural world from anatomy to aerodynamics.

Further development in the field of Rhinology transpired in Italy with two great surgeons ie, , Branka and Tagliacozzi around $1500 \mathrm{AD}$. During this time there were several wars being fought in Europe. Syphilis was rampant in the society resulting in nasal deformities and the interest in the nasal reconstruction was kindled. Branka and Tagliacozzi, the two Italian physicians developed an arm pedicle flap for mutilated noses. Tagiacozzi, a professor of anatomy and medicine at Bologna University published a series of 40 patients of rhinoplasty in 1597 and became quite popular in Europe. This was the beginning of the serious attempt of corrective rhinoplasty, as we know today. Further development continued in the field of anatomy in the renaissance period with the tremendous work by Andreas Vesaleus in 1537 . He was a lecturer in Padua University at the age of $28 \mathrm{yr}$. He had a great passion for studying human anatomy and he corrected many errors of Greek physician Galen (131-201 AD) based on anatomical dissection on animals. He published his magnificent book on anatomy printed in Basel in Switzerland in June 1543.He was a master of many languages such as Greek, Latin, Hebrew and Arabic. He described maxillary, frontal, and sphenoid sinuses as air containing cavities and gave detail description of the anatomy of the middle ear. In the next less $20 \mathrm{yrs}$, he published second book on anatomy, this time with addition of physiology. In spite of greater understanding of anatomy and aesthetics of the nose some surgeons were not convinced of the reconstructive rhinoplasty. Artificial noses were first described in 669-711 AD but were not popular. A French military surgeon, Ambroise Pere, redesigned artificial noses in 1517 AD. He made artificial nose of silver which was held in place with a fine string made of gold and leather. Later Tyche Brahe in 1546 made noses of alloy of copper and silver.

A sudden surge in the magnification of the reconstructive surgery of the nose materialised when two British surgeons, Thomas Cruso and James Findlay observed a forehead flap reconstruction of the nose on a prisoner of war named Cowesjee, captured in a war with Tipu Sultan in 1794 in India. These two British surgeons described the operation in detail and reported as a curious operation of a new nose in October 1794 in London. This marked the beginning of interest in rhinoplasty in Europe. Based on this Indian method of rhinoplasty, described by Sushruta, a British surgeon J.C. Corpue was the first surgeon to perform Indian rhinoplasty in London in October 1814.Subsequently the method was introduced in Germany by Von Graefe in 1816 and later by Dieffenbachia in 1829. Lisfranc made the technique popular in France in 1827, by Warren in 1837 in North
America. John Roe 1887 and Weir in 1892 popularised intranasal approach and tackled tip plasty, hump removal, alar resection and published their techniques in detail. In 1889 a Chief Medical Officer from Junagadh state in India Dr.Tribhuvandas Motichand Shah wrote a monograph on rhinoplasty based on his experience of 100 cases of reconstructive rhinoplasty over a period of five years. Keegan in 1900 wrote a monograph on his experience of rhinoplasty during his work in a charitable hospital in Indore, in India. He quoted in his book that during 1897 there were 152 cases of reconstructive nasal surgery performed in India..

\section{Modern Era}

The modern era of rhinoplasty as we know today began in 1898 with the work, not of a ENT surgeon but an orthopaedic surgeon from Berlin, named Jacque Joseph. He was not a very popular surgeon among his colleagues but had contributed a great deal to the technique of rhinoplasty. He described in detail reduction rhinoplasty for the hump and other specific deformities. He particularly drew attention to the social and psychological factors to be taken into consideration prior to rhinoplasty. He also designed several instruments, which are being used today. He published a paper on surgical correction of the nose in great detail and established intranasal rhinoplasty in Europe on a scientific basis at the turn of the 20th Century. He also published a comprehensive book on rhinoplasty in 1928. At the same time John Roe in New York continue to perform corrective rather than reconstructive surgery and popularised intracartilagenous approach to the bulbous tip.

\section{Surgery of the Septum and Paranasal Sinuses}

In relation to the rhinoplasty operation, surgery of the septum did not develop until late 19th century. Asch in 1890 noticed many large septal perforations following septectomy which was a common operation then, and suggested fracturing and repositioning the septum. This was also not successful and Killian in 1904 and Freer in 1905 described sub mucous resection of the nasal septum. Later on Metzenbaun in 1929 corrected caudal dislocation of the septum and described swinging door technique for the deviated septum. In the middle of the 20th century Becker (1951), Goldman(1956), and Cottle (1958) established the concept of septoplasty, which is performed today. These workers emphasised the importance of conservative surgery on the septum and suggested correction of the deviated parts of the septum. With the advent of nasal endoscopes, endoscopic septoplasty is increasingly performed targeting only the deviated parts of the septum with the help of an endoscope.The endoscope provides excellent visualisation and precise location of the deviated parts of the septum. This alleviates the need for the 
complete separation of the perichondrium either one or both sides of the septum and reduces the chances of postoperative septal haematoma.

Following Sushruta's "Netiyantra" to examine the nose, Pere Dionis described first nasal speculum in 1714. Examining nasal polypi with his speculum he also tried to explain the origin of nasal polyp. More than a century later Czemark in 1858 designed a mirror rhinoscopy. The quest to look into the nose and especially into the sinuses continued with Wertheim in 1896 designing a "conchoscope" to look deeper into the middle meatus. At this stage in the history cocaine was discovered and found to be extremely useful as a local anaesthetic and a powerful vasoconstrictor agent. Gustav Killian became more curious to look further into the nasal cavity and designed a long nasal speculum which bears his name today. A major breakthrough in the examination of the nose and sinuses was realised when Alfred Hirschman in 1901 used a cystoscope which he modified to $4 \mathrm{~mm}$ in diameter to look into the maxillary sinus through an extracted molar tooth socket. Later he studied middle meatus and sinus ostia with the same endoscope.

Although Andreas Vesalius in 1537 described maxillary sinus as an air containing cavity, very little was known about the maxillary sinus. It was not until Nathan Highmore, an Englishman from Dorset saw a female patient on one weekend, who came to see him in panic with a piece of feather stuck in her mouth as she was cleaning her extracted tooth socket. While cleaning she accidentally pushed the feather deep inside and thought that the feather had entered into the brain! Highmore removed the foreign body and wondered about a empty space between the mouth and the brain. Later he named the maxillary sinus as Antrum (A cavity) of Highmore in 1651 . The main disease affecting maxillary sinus at this time was an empyema which was treated with the extraction of the molar tooth and creating a permanent oroantral fistula. Following Highmore's anatomical description of the sinus, Antonio Mollinetti in 1675 incised and trephined the maxillary sinus rather than going through the tooth socket. William Cowper in 1717 advocated regular sinus washouts following trephination. He contributed a chapter on the diseases of the nose in a book named "Anthropologia Nova" in 1717. Meantime Lamorier in France in 1743, described external approach to the infected maxillary sinus and presented his technique at the Royal Academy meeting in Paris. These radical procedures for the common sinus disease were not very popular with permanent OAF. As a result alternative technique of clearing the infected sinus with trocar and canula through the inferior meatus was designed by Mikilicz and Lichtwitz in 1886 which is still being used in some ENT departments. Zukerkandle in 1882 and Onodi in 1902 along with Siebenmann and Killian in 1900 advocated middle meatal antrostomy but did not practiced due to poor visualisation and fear of orbital complications. Simple washing of the sinus through the inferior meatus did not solve the problem of the chronic infection of the maxillary sinus. A New York surgeon George Cald Well in 1893 described a procedure of entering into the maxillary sinus through the canine fossa, removing the diseased mucous membrane and making a permanent opening in the inferior meatus to drain the sinus. Incidentally another surgeon in France named Henry Luc was also working on the same operation, which then was commonly described as Cald Well Luc operation. Lothrop in 1897 recognised early closure of inferior meatal antrostomy and Freer in 1905 strongly advised against radical operations and understood the need for ventilation of the maxillary sinus. Once again there was a disappointment for the patients as the patients continued to have symptoms. At the turn of the 20th century Killian and Siebenmann (1900-1910) advocated drainage though the middle meatus by performing uncinectomy for the infection of the maxillary sinus.

With better visualisation of the nasal cavity, ParsonSchaefer in 1912-1923 described intricate anatomy of the lateral wall of the nose and ethmoid sinuses. Harris Mosher from MI, Boston, in 1929 described anatomy of ethmoid sinuses in great detail. He also emphasised the importance of Agger nasi cells to the frontal sinus surgery. Describing ethmoid sinuses and its relations to the skull base and orbit he stated that the operation of intra nasal ethmoidectomy was the "easiest way to kill a patient".

\section{The sinus revolution}

With rapid advancement in the field of technology and science, the new era was dawn in treating chronic sinus disease. The visualisation with the fibre optics of the nose and sinuses continued at a rapid space and conventional telescopes were used which contained single lenses inside a solid metal tube. These later were replaced by a splendid invention of solid rod lens by Prof. Hopkins which heralded a new era in the field of Endoscopy in 1954. With the help of improved examination of the nose and sinuses Prof. Walter Messeklinger in Austria studied mucociliary mechanism of the paranasal sinuses. In fact King in 1935 already demonstrated that cilia of in the maxillary sinus drain the mucus towards the natural ostium inspite of a large dependent opening being present in the sinus. Prof. Messerklinger in 1967 studied and documented these genetically determined pathways of mucociliary mechanism in all sinuses and postulated that cilia always drain the mucus towards the natural ostium and any obstruction to these natural drainage was responsible for the continued sinus infection. He emphasised that the anterior ethmoid and ostiometal complex was the "key" to the chronic sinus disease. This formed the basis for the pathophysiology of chronic recurrent sinusitis. Prof. Messerklinger in Austria and Prof. Draf in Germany later published their experience in nasal endoscopy, the importance of precise diagnosis and its application in sinus surgery in 1978 and 1983 respectively. The advent of CT 
imaging and multiangled endoscopes further enhanced the scope of non invasive, non radical sinus surgery which is more functional ie, improving the ciliary mechanism of the mucous membrane. As ENT surgeons are familiar with use of microscope, Prof. Draf combined the use of microscope and endoscope, thus allowing both hands to be used during surgery in the initial stages. He recommended use of endoscope deep into the cavity of the nose for further surgery. Prof. Draf also paved the way to non invasive approach to various skull base pathology, including surgery of the frontal sinus, where he described Draf I, II, and III procedures for the permanent drainage of the frontal sinus through their natural ostia. Later on Prof. H.Stammberger popularised the technique and published his experience in Endoscopic sinus surgery in 1991.

\section{New horizons}

In recent years endoscopes has been used for various pathologies in the nose and sinuses in addition to the treatment of chronic sinus disease. It is now common to use endoscopes to deal with posterior epistaxis, Sphenopalatine artery ligation, removal of mucoceles, certain benign tumours, and repair of CSF leak, Pituitary surgery and endoscopic management of orbital and skull base lesions. With further development of new generation of thru' cut instruments, lasers, microdebriders, image guided surgery, radio frequency etc.surgery has become ultra conservative. The major external operations on paranasal sinuses including obliteration are certainly less commonly performed mitigating considerable morbidity and external scars associated with these procedures.

\section{Final thought}

The nose and sinus surgery being radical in 1884 became somewhat conservative with the discovery of antibiotics, and better understanding of the pathophysiology in the middle of the 20th Century. I believe the modern surgeon should be a clinician first, then a surgeon. The clinician, inspite of all the high tech equipments, must approach the disease process by resolute history, examination and relevant investigations to understand the precise nature of the problem. Then only if necessary he/she should embark upon surgery, which also should be minimal, just to help the nature to help herself. To reiterate Paracelsus, a Swiss physician who wrote in 1493 regarding treating patients that "Nature heals under the auspices of medical profession". The clinician should take the advantage of modern equipments to diagnose the disease rather than just use a tool to perform more operations! We all learn, from our patients, and must be prepared to change our practice accordingly for the benefit of the patients. Certain procedures ie, inferior turbinate surgery or radical procedures on the nasal septum or external pyramid or sinuses need to be appraised with more respect to the structure and function provided by the "Mother Nature" which Suhruta and Hippocrates believed so passionately. Today's physician must not and should not rely upon equipments only as these do not and will not substitute basic clinical.

The art of healing comes from nature not from the physician. Therefore the physician must start from nature, with an open mind.

The ENT surgeon has come a long way throughout the centuries with the improved understanding of the diseases, technological innovations etc. but under no circumstances we should overlook the fact that it must be for the benefit of the patient who place their trusts in the doctor. Unfortunately disastrous complications have occurred with several new techniques and proper training with sound knowledge of anatomy, physiology and pathology is of utmost importance. The technological advances should not be allowed to take over basic bed side medicine, history and examination. There are some patients whom we cannot help, but there are none whom we cannot harm..

An eminent, Greek philosopher Plato (427-347 BC), wrote that medicine is an art, and attend to the nature and constitution of the patient, and has principals of action and reason in each case. Thomas Szasza, a psychiatrist said," Formerly when religion was strong and science weak, men mistook magic for medicine, now when science is strong and religion weak, men mistake medicine for magic! 